\title{
Conceptual modeling of temperature effects on capillary pressure in dead-end pores
}

\author{
DEBRAJ BISWAS* and SURESH A KARTHA
}

Department of Civil Engineering, Indian Institute of Technology Guwahati, Guwahati, Assam 781039, India e-mail: debraj.biswasjgec@gmail.com; kartha@iitg.ac.in

MS received 8 July 2017; revised 23 November 2018; accepted 4 February 2019; published online 20 April 2019

\begin{abstract}
The effect of temperature on the liquid-gas interface and consequently on the capillary pressure in unsaturated dead-end pores is conceptually modeled in this paper. Trapping of non-wetting fluid (e.g., air) in the dead-end pores impacts the capillary pressure-saturation relationship and affects the continuous flow of wetting fluids. In the dead-end pore, which is assumed to be a simple vertical cylindrical capillary tube with one end closed and the other end open to the liquid body, the dependence of solid-liquid and solid-air interfacial tensions on temperature and its subsequent effects on the contact angles are deduced. A non-linear ordinary differential equation, using the Young-Laplace equation, in terms of a contact-angle-sensitive temperature function is derived and numerically solved using the fourth order Runge-Kutta method. This temperature function is used to obtain the capillary pressure-temperature relationship for a solid-liquid-air capillary system. Two example problems, first a glass-water-air capillary system and second a polytetrafluoroethylene-n-hexadecane-air capillary system, are solved here. A linear decrease in capillary pressure with temperature is observed, suggesting that entrapped air affects capillary pressure in dead-end pores. A similar linear decrease in capillary pressure, consistent with experimental observations, is observed for open-end pores.
\end{abstract}

Keywords. Dead-end pores; Young-Laplace equation; capillary pressure; temperature; numerical modeling.

\section{Introduction}

Void space in unsaturated soil consists of two phases of fluid - wetting and non-wetting. Two-phase flow in unsaturated soil is governed by capillary pressure vs. saturation relationship (CPSR) [1] and is generally obtained through some standard empirical relationships [2,3] fitted to experimental data for a particular soil. Capillary pressure is defined as the pressure difference across the interface of the two immiscible fluids - wetting and non-wetting fluids, and is determined by the surface tension and curvature of the interface [4]. In a wet situation, the residual non-wetting fluid remains trapped in the crevices of pores or in dead-end pores due to the presence of wetting fluid and provides an interface between wetting and non-wetting fluids. During air sparging, which is a groundwater re-mediation technique to displace water with the injection of air, there are chances that the air bubble remains in dead-end pores [5]. Dead-end pores are also known as stagnant pockets [6]. Their geometry, i.e. closed end (one end is closed and other is connected to the active pores), makes the fluids in these zones stagnant as the name suggests. Thus any change in these zones affects capillary pressure or CPSR for a given degree of saturation and affects the flow characteristics in the soil. Trapping of non-wetting

*For correspondence fluid is one of the reasons for the hysteresis effect of CPSR and vice versa [7]. Appropriate drainage of irrigated lands is one of the most important factors in improving the yield from agricultural fields as well as preventing water logging and salinity $[8,9]$. During the subsurface drainage of excess liquid from irrigated lands, the liquid starts to come from all corners of soil to the main pore channels and subsequently moves to the ditches or perforated pipes. However, due to suction or capillary pressure, the liquids from the stagnant zones contribute less to the flow and may also resist the drainage flow. Thus dead-end pores can play a role during the drainage phenomena through soil pores.

The increase in surface and subsurface infrastructures to accommodate the needs of ever-rising human population, along with global warming, has led to the rising of subsurface temperature $[10,11]$. Temperatures in and around big cities are becoming high to higher and this is known as urban heat island effect [12-16]. This has a further impact on the groundwater hydrology [17] and has already affected all the terrestrial water storage (sum of groundwater, soil moisture, surface water, snow and ice) [18]. Subsurface temperature can affect the physics of fluid inside the soil in terms of capillary pressure. In this paper, we attempt to gain a conceptual insight into the temperature effects on capillary pressure inside the dead-end pores that to the best of our knowledge hitherto has been very rarely studied. 
Dead-end pores are generally studied in reference to diffusion within mobile and immobile or dead-end pores [19-23] and in reference to oil recovery through different techniques [24-29]. Therefore this paper tries to understand the much overlooked dead-end pores of soil and their influence on the flow characteristics in terms of capillary pressure (as also mentioned by Fatt [30]). Temperature effects on capillary pressure in general were studied by many researchers [31-35] and are found to be elusive still today. This paper considers the dead-end pore as a capillary tube with one end closed and another end in touch with an infinite source of wetting fluid. This assumption is justified as one end of dead-end pores is usually connected to the main flow channel or active pores. Air is taken as non-wetting fluid in this study. The Young-Laplace equation is invoked and differentiated with respect to temperature with some assumptions for our problem domain. A differential equation of a temperature function is obtained and consequently, capillary pressure is deduced from this function. Through example problems, we present the effects of properties of air, liquid, and solid as well as the physical dimension of the dead-end pore on capillary pressure-vs.-temperature relation. In a subsequent section, the capillary pressure-vs.-temperature relation is derived in the same way for an open-end capillary tube for comparison purposes.

\section{Mathematical modeling}

In this paper, capillary pressure $\left(P_{\mathrm{c}}\right)$ is introduced as an explicit function of two distinct variables - temperaturedependent variables (say, $G(T)$ ) and temperature-independent variables (say, $M$ ) i.e. $P_{\mathrm{c}}(T)=P_{\mathrm{c}}(G(T), M)$. The capillary pressure $v s$. temperature is assumed to be a nonhysteric one for a particular liquid saturation, as suggested and verified by researchers $[33,34,36]$. Therefore, a single relationship will be sufficient for both heating and cooling curves, i.e. both curves are actually the same - no hysteresis - no two values of $P_{\mathrm{c}}$ at single $T$. Then the total derivative of $P_{\mathrm{c}}(G, M)$ with respect to temperature $T$ will be

$$
\frac{d P_{\mathrm{c}}}{d T}=\frac{\partial P_{\mathrm{c}}}{\partial G} \frac{d G}{d T}+\frac{\partial P_{\mathrm{c}}}{\partial M} \frac{d M}{d T}=\frac{\partial P_{\mathrm{c}}}{\partial G} \frac{d G}{d T}+0=\frac{\partial P_{\mathrm{c}}}{\partial G} \frac{d G}{d T} .
$$

Similarly, from here onwards, it is assumed that every other physical property is either a function of temperature (like $G(T)$ ) or not (like $M$ ). Under static equilibrium scenario in a cylindrical capillary tube with a spherical meniscus (assumed) (figure 1), the Young-Laplace equation is [37]

$$
P_{\mathrm{c}}=\frac{2 \sigma}{r} \cos \theta,
$$

where $\sigma$ is the surface tension of the liquid $(\mathrm{N} / \mathrm{m}), \theta$ the contact angle between the air-liquid interface and the solid surface (deg) and $r$ the radius of the capillary tube (m). The Young's equation at static equilibrium is [38]

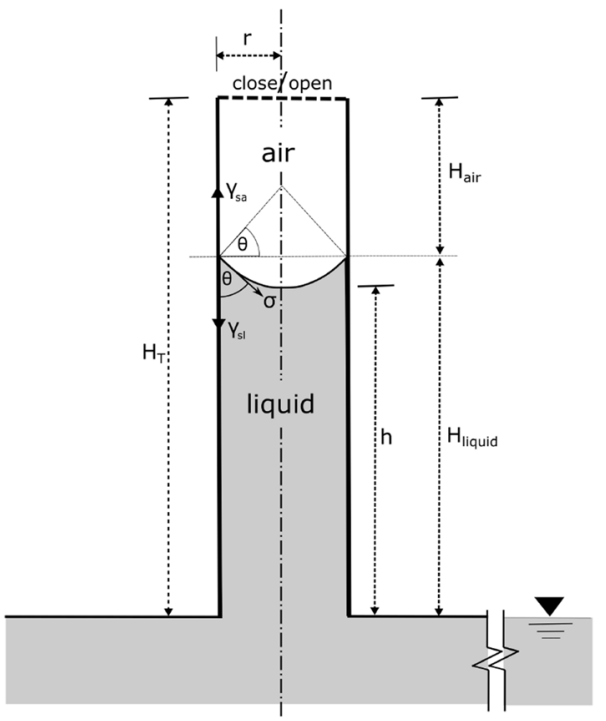

Figure 1. A schematic of liquid rise in a capillary tube.

$$
\gamma_{\mathrm{sa}}-\gamma_{\mathrm{sl}}=\sigma \cos \theta
$$

where $\gamma_{\mathrm{sl}}$ is the interfacial tension between solid and liquid surfaces $(\mathrm{N} / \mathrm{m})$, and $\gamma_{\mathrm{sa}}$ is the interfacial tension between solid and air surfaces $(\mathrm{N} / \mathrm{m})$.

Assuming that the whole system is in static equilibrium in capillary tube, the capillary pressure at the interface or meniscus is $P_{\mathrm{c}}=P_{\text {air }}-P_{\text {liquid }}$, where $P_{\text {air }}$ is the pressure of air in the closed section of the tube $\left(\mathrm{N} / \mathrm{m}^{2}\right.$ or $\left.\mathrm{Pa}\right)$ and $P_{\text {liquid }}$ is the pressure in liquid immediately under the meniscus (Pa) $[37,39]$. Air in the closed section is assumed to be an ideal gas (where there are no intermolecular forces and interactions among gas molecules) and thus follows the ideal gas law [40]:

$$
P_{\text {liquid }}=\frac{n R T}{V_{\text {air }}}-P_{c},
$$

where $R$ is universal gas constant $(\mathrm{N}-\mathrm{m} / \mathrm{K}$-mol), $n$ number of moles of gas (or air) (mol), $T$ temperature $(\mathrm{K})$ and $V_{\text {air }}$ volume of air $\left(\mathrm{m}^{3}\right)$.

The liquid pressure in the capillary tube is assumed to conform to the law of hydrostatics [39]. Since the pressure in the liquid is connected to an active or main channel, the pressure in the liquid in capillary gets reduced towards meniscus level above the channel and thus the liquid pressure at the bottom of the meniscus is

$$
P_{\text {liquid }}=P_{\text {ref }}-\rho g h,
$$

where $P_{\text {ref }}$ is the pressure at the bottom of the tube (taken as atmospheric pressure like water table, $P_{\text {atm }}$ for simplicity and assumed to be temperature-independent) (Pa), $\rho$ the density of liquid $\left(\mathrm{kg} / \mathrm{m}^{3}\right), g$ the acceleration due to gravity $\left(9.81 \mathrm{~m} / \mathrm{s}^{2}\right)$ and $h$ the height of liquid rise in the tube (m) (see figure 1).

Comparing Eqs. (4) and (5), we have 


$$
P_{\mathrm{atm}}+P_{\text {liquid }}^{\prime}=\frac{n R T}{V_{\mathrm{air}}}-P_{\mathrm{c}}
$$

where $P_{\text {liquid }}^{\prime}=\rho g(-h)$.

As air cannot escape in the case of closed-end pore, the mass of air will be a constant, and therefore, the number of moles of air $(n)$ is treated as a temperature-independent variable. Differentiating Eq. (6) with respect to temperature $T$ and with the help of Eqs. (2) and (3), we get

$$
\frac{d P^{\prime}}{d T}=\frac{n R}{V_{\text {air }}}-\frac{n R T}{V_{\text {air }}^{2}} \frac{d V_{\text {air }}}{d T}-\frac{2}{r}\left(\frac{d \gamma_{\mathrm{sa}}}{d T}-\frac{d \gamma_{\mathrm{sl}}}{d T}\right) .
$$

Volume of the air section above the air-liquid interface in the capillary tube can be rearranged to get a contactangle-sensitive temperature function $f_{\theta}(T)$ as follows:

$$
\begin{gathered}
V_{\text {air }}=\pi r^{2} H_{\text {air }}+\frac{\pi r^{3}}{\cos ^{3} \theta}\left(\frac{1}{3} \sin ^{3} \theta-\sin \theta+\frac{2}{3}\right), \\
\frac{V_{\text {air }}}{\pi r^{3}}-\frac{H_{\text {air }}}{r}=\frac{1}{\cos ^{3} \theta}\left(\frac{1}{3} \sin ^{3} \theta-\sin \theta+\frac{2}{3}\right)=f_{\theta}(T),
\end{gathered}
$$

where $H_{\text {air }}$ is the height of the air section in the capillary tube $(\mathrm{m})$ (see figure 1).

According to studies done by other researchers [38, 41-43], the liquid-air interface or meniscus can adjust itself for small pressure changes to nullify the imbalance without any vertical movement. Hence the meniscus gets stuck or pinned at the hardly smooth natural surface of the solid. This pinning phenomenon or formally contact line pinning (CLP) causes the contact angle hysteresis (a difference between the maximum and minimum $\theta$ ) [44]. Contact angle hysteresis, therefore, suggests that there is no unique value for contact angle even at static equilibrium [45]. The authors in this research opine that this phenomenon may or is rather probable to happen for temperature variation within a certain range of temperatures (say $\Delta T)$. Within this range, meniscus behaves as elastic and liquid sticks to the solid surface before meniscus starts moving (after surpassing some energy barrier [see [46, 47], for more details]). As an example, it takes $T \sim 10^{3} \mathrm{~K}$ for water-air meniscus even to overcome one nanometer of defect on quartz glass substrate if pinned [48-50]. Thus, CLP implies that $H_{\text {air }}$ is independent of temperature within this small interval of temperature, in which the translation motion of the meniscus along the solid surface is absent, i.e. $d H_{\text {air }} / d T=0$.

Applying the assumption of $d H_{\text {air }} / d T=0$, substituting Eq. (8b) in Eq. (7) and after some simplifications, we have

$$
\begin{aligned}
& n R T \frac{d f_{\theta}(T)}{d T}=n R\left(f_{\theta}(T)+\frac{H_{\mathrm{air}}}{r}\right) \\
& -\pi r^{3}\left(f_{\theta}(T)+\frac{H_{\text {air }}}{r}\right)^{2} \frac{d P^{\prime}{ }_{\text {liquid }}}{d T} \\
& -2 \pi r^{2}\left(f_{\theta}(T)+\frac{H_{\mathrm{air}}}{r}\right)^{2}\left(\frac{d \gamma_{\mathrm{sa}}}{d T}-\frac{d \gamma_{\mathrm{sl}}}{d T}\right) .
\end{aligned}
$$

Grant [34] argued that interfacial tension is a linear function of temperature, and the difference of their temperature derivatives $\left(d \gamma_{\mathrm{sa}} / d T-d \gamma_{\mathrm{sl}} / d T\right)$ in Eq. (9) becomes a constant (let us say this constant is $C_{\gamma}$ ).

Meniscus height $H_{\mathrm{m}}$ is deduced as (see figure 1)

$$
H_{\mathrm{m}}=H_{\text {liquid }}-h=r(\sec \theta-\tan \theta),
$$

where $H_{\text {liquid }}$ is the height of the liquid section. Equation (8b) can be rewritten with help of Eq. (10) in terms of $H_{\mathrm{m}}$ as

$$
H_{\mathrm{m}}^{3}+\left(3 r^{2}\right) H_{\mathrm{m}}+\left(-6 r^{3} f_{\theta}\right)=0 .
$$

On solving Eq. (11), we have three roots for $H_{\mathrm{m}}$, among which one is a real root and other two are conjugate complex roots. The real root of Eq. (11) is

$$
\begin{aligned}
H_{\mathrm{m}}\left(f_{\theta}\right)= & -\frac{r^{2}}{\left(3 f_{\theta} r^{3}+\sqrt{r^{6}+9 f_{\theta}^{2} r^{6}}\right)^{1 / 3}} \\
& +\left(3 f_{\theta} r^{3}+\sqrt{r^{6}+9 f_{\theta}^{2} r^{6}}\right)^{1 / 3} .
\end{aligned}
$$

From Eq. (6) $P_{\text {liquid }}^{\prime}=-\rho g h=-\rho g\left(H_{\text {liquid }}-H_{\mathrm{m}}\left(f_{\theta}\right)\right)$ (see figure 1). The derivative of $P_{\text {liquid }}^{\prime}$ with respect to $T$ is

$$
\frac{d P^{\prime}{ }_{\text {liquid }}}{d T}=\rho g \frac{d H_{\mathrm{m}}}{d f_{\theta}} \frac{d f_{\theta}}{d T},
$$

since $H_{\text {liquid }}$ is constant due to CLP condition. Substituting Eq. (13) in (9) and performing some arithmetic operations and simplifications, a differential equation of $f_{\theta}$ with respect to $T$ is obtained:

$$
\begin{aligned}
T \frac{d f_{\theta}}{d T} & +\rho(T)\left[\left(A_{1} f_{\theta}^{2}+A_{2} f_{\theta}+A_{3}\right) \frac{d H_{\mathrm{m}}}{d f_{\theta}}\right] \frac{d f_{\theta}}{d T} \\
& +\left(B_{1} f_{\theta}^{2}+B_{2} f_{\theta}+B_{3}\right)=0,
\end{aligned}
$$

where the intermediary temperature-independent terms are

$$
\begin{aligned}
A_{1} & =\frac{g \pi r^{3}}{n R}, A_{2}=\frac{2 g \pi r^{2} H_{\mathrm{air}}}{n R}, \\
A_{3} & =\frac{g \pi r H_{\mathrm{air}}^{2}}{n R}, B_{1}=\frac{2 \pi r^{2} C_{\gamma}}{n R}, \\
B_{2} & =\frac{4 \pi r H_{\mathrm{air}} C_{\gamma}}{n R}-1, B_{3}=\frac{2 \pi H_{\mathrm{air}}^{2} C_{\gamma}}{n R}-\frac{H_{\mathrm{air}}}{r} \text { with } \\
\frac{d H_{\mathrm{m}}}{d f_{\theta}} & =\frac{r^{3}\left[r^{2}+\left(3 f_{\theta} r^{3}+D\right)^{2 / 3}\right]}{D\left(3 f_{\theta} r^{3}+D\right)^{1 / 3}} \text { where } D=\sqrt{\left(r^{6}+9 f_{\theta}^{2} r^{6}\right)} .
\end{aligned}
$$

Equation (14) is a non-linear first-order ordinary differential equation. Equation (14) can be solved using an analytical or numerical method. In this paper, we solve Eq. (14) using the fourth-order Runge-Kutta (RK4) numerical method (see [51] to know more about RK4). 
At a particular temperature (say $T_{\mathrm{p}}$ ), liquid rises through capillary effect through the open-end section of the oneend-closed capillary tube. The calculation of the number of moles of gas before and after the capillary rise is as follows. Before the liquid starts to enter into the tube, only air molecules fill up the tube. Initially let the number of moles of air be $n_{\mathrm{i}}$. After a certain time, the liquid meniscus will reach some height and stop, and the whole system reaches static equilibrium. Again, let the number of moles of air in the portion between the water meniscus and top closed end of the capillary tube be $n_{\mathrm{f}}$. It is assumed that there is no loss of air molecules or no air is dissolved in the liquid from the moment of touch of the capillary tube on the water surface in the infinite reservoir to the time to reach Jurin height. Then the number of moles of air is $n_{\mathrm{i}}=n_{\mathrm{f}}=n$. Accordingly, the number of moles of air is

$$
n=\frac{\left(P_{\text {air }}\right)_{\mathrm{i}}\left(V_{\text {air }}\right)_{\mathrm{i}}}{R T_{\mathrm{p}}},
$$

where $\left(P_{\text {air }}\right)_{\mathrm{i}}=P_{\text {ref }}=P_{\text {atm }},\left(V_{\text {air }}\right)_{\mathrm{i}}=V_{\mathrm{T}}=\pi r^{2} H_{\mathrm{T}}=$ total volume of the capillary tube and $H_{\mathrm{T}}$ is the total height of the capillary tube $(\mathrm{m})$.

Capillary pressure can be evaluated from Eq. (6) as a function of temperature, i.e. as temperature function $f_{\theta}(T)$, which can be obtained from Eq. (14) as

$$
\begin{aligned}
P_{\mathrm{c}} & =\frac{n R T}{V_{\mathrm{air}}}-P_{\mathrm{atm}}+\rho g h, \\
P_{\mathrm{c}}(T) & =\frac{n R T}{V_{\text {air }}\left(f_{\theta}(T)\right)}-P_{\mathrm{atm}}+g \rho(T)\left(H_{\text {liquid }}-H_{\mathrm{m}}\left(f_{\theta}(T)\right)\right) .
\end{aligned}
$$

In Eq. (14) as well as in Eq. (16), the density of liquid $(\rho(T))$ can be given as direct input through available empirical relationship of density of liquid $v s$. temperature from different sources $[52,53]$.

\section{Results}

The concepts developed in Section 2 to determine the capillary pressure for solid-liquid-gas system in a closedend capillary tube that mimics the dead-end pores in soils are used to solve two example problems as shown below.

\subsection{Example 1 (solid: glass and liquid: water)}

A glass-water-air ( $\mathrm{G}-\mathrm{W}-\mathrm{A})$ combination is considered as the solid-liquid-gas system in this example for the capillary action. One end of the cylindrical glass tube is open and the other end is closed. Let the temperature of air in the empty closed-end cylindrical capillary glass tube be initially 298.15 $\mathrm{K}$ (figure 1). The Standard Temperature and Pressure (STP) used in this research have the temperature value at $298.15 \mathrm{~K}$ and pressure at $101325 \mathrm{~Pa}$. The empty glass tube is placed inverted with the closed end at the top and the open end just touching the water surface in the reservoir (figure 1). After a certain time, water rises to the Jurin height, $h=$ $\left(2 \sigma \cos \theta_{\text {eq }}\right) /(r \rho g)$ under static equilibrium [39] $\left(\theta_{\text {eq }}\right.$ is the contact angle at the static equilibrium, i.e., static contact angle or otherwise known as equilibrium contact angle [54]). The assumption here is that the Jurin height or capillary rise will be the same for the closed-end capillary tube. This assumption is kept valid by keeping the Bond number $(\mathrm{Bo})$ [55] to be much less than 1, i.e. assuring that the surface forces will be dominant. Therefore, the condition for the radius of the tube is $r \ll \sqrt{(\sigma / \rho g)}$. The radius of the tube is assumed based on the soil pore size, i.e. approximately $50 \mu \mathrm{m}$ [56, see table 2] satisfying the afore-mentioned condition of $\mathrm{Bo}$. The total height of the capillary tube, which is $0.50 \mathrm{~m}$, is based on the assumption that the total height has to be more than the maximum possible Jurin height (i.e. the capillary height when $\theta_{\text {eq }}=0^{\circ}$ ). Table 1 gives the necessary values of the parameters of the system. From experimental results of Liechti et al [57], and studies from Dean [52] and Mohr et al [58], the parameters for this example analysis are adopted.

First, the function $f_{\theta}(T)$ is calculated for the desired temperatures from the given reference temperature (i.e. $298.15 \mathrm{~K}$ ). To solve Eq. (14), the values of the intermediary terms $A_{1}, A_{2}, A_{3}, B_{1}, B_{2}$ and $B_{3}$ are needed. For the computation of these six intermediary terms, three parameters, i.e. $H_{\text {air }}, n$ and $C_{\gamma}$, are evaluated from the basic parameters given in table 1 . The steps to calculate these three parameters are as follows: (a) $H_{\text {air }}$ can be calculated as $H_{\text {air }}=$ $H_{\mathrm{T}}-\left(H_{\mathrm{m}}+h\right)\left(H_{\mathrm{m}}\right.$ can be obtained from Eq. (10) with $\theta_{\text {eq }}$ ), (b) $n$ can be obtained from Eq. (15) taking $T_{\mathrm{p}}$ as initial temperature, $298.15 \mathrm{~K}$ and (c) the solid interfacial surface energies are evaluated from the following equations (found from Girifalco and Good [59] using Eq. (3)) using empirical laws of contact angle, surface tension of liquid and liquid density variations with temperatures.

Interfacial energy between glass and air can be calculated as

$$
\gamma_{\mathrm{ga}}(T)=\sigma(T)\left(\frac{(1+\cos \theta(T))^{2}}{4(\Phi(T))^{2}}\right),
$$

and interfacial energy between glass and water can be as

$$
\gamma_{\mathrm{gw}}(T)=\sigma(T)\left(\frac{(1+\cos \theta(T))^{2}}{4(\Phi(T))^{2}}-\cos \theta(T)\right),
$$

where $\Phi(T)=4\left(\mathcal{V}_{\mathrm{g}} \mathcal{V}_{\mathrm{w}}(T)\right)^{1 / 3}\left(\mathcal{V}_{\mathrm{g}}^{1 / 3}+\left(\mathcal{V}_{\mathrm{w}}(T)\right)^{1 / 3}\right)^{-2}$ and $\mathcal{V}_{\mathrm{g}}, \mathcal{V}_{\mathrm{w}}$ are molar volumes of glass and water, respectively. Molar volumes: $\mathcal{V}_{\mathrm{g}}=\mathcal{M}_{\mathrm{g}} / \rho_{\mathrm{g}}=\left(60.45 \times 10^{-3} \mathrm{~kg} / \mathrm{mol}\right) /$ $\left(2.52 \times 10^{3} \mathrm{~kg} / \mathrm{m}^{3}\right)=23.99 \times 10^{-6} \mathrm{~m}^{3} / \mathrm{mol}[61]$ and $\mathcal{V}_{\mathrm{w}}=$ $\mathcal{M}_{\mathrm{w}} / \rho(T)=\left(18 \times 10^{-3} \mathrm{~kg} / \mathrm{mol}\right) / \rho(T)$, where $\mathcal{M}_{\mathrm{g}}$ and $\mathcal{M}_{\mathrm{w}}$ represent the molar masses of glass and water, respectively $(\mathrm{kg} / \mathrm{mol})$ and $\rho_{\mathrm{g}}$ and $\rho(T)$ are densities of glass 
Table 1. Parameters used for calculation in glass-water-air system.

\begin{tabular}{lccc}
\hline Parameter & Description & Value & Reference \\
\hline$\sigma$ & Surface tension of water at $298.15 \mathrm{~K}$ & Dean [52] \\
$\rho$ & Density of water at STP & $71.99 \times 10^{-3} \mathrm{~N} / \mathrm{m}$ & Dean [52] \\
$g$ & Acceleration due to gravitation & $996.66 \mathrm{~kg} / \mathrm{m}^{3}$ & Mohr et al [58] \\
$\theta_{\text {eq }}$ & Equilibrium contact angle of water on glass & $9.81 \mathrm{~m} / \mathrm{s}^{2}$ & Liechti et al $[57]$ \\
$r$ & Radius of the tube & $50^{\circ}$ & Assumed \\
$R$ & Universal gas constant & $50 \times 10^{-6} \mathrm{~m}$ & Mohr et al $[58]$ \\
$H_{\mathrm{T}}$ & Total glass tube height & $8.314 \mathrm{~N}-\mathrm{m} / \mathrm{K}-\mathrm{mol}$ & Assumed \\
\hline
\end{tabular}

and water, respectively $\left(\mathrm{kg} / \mathrm{m}^{3}\right)$. Thermal sensitivity of glass is neglected and throughout the paper, the thermal sensitivities of solids in general are neglected because of low thermal coefficient values compared with the liquid counterpart. Data of temperature variations of density, contact angle and surface tension of water are obtained from Dean [52], Neumann [62] and Vargaftik et al [63], respectively. Using Eqs. (17) and (18), figure 2 is drawn for different temperatures using available data of the literatures. Linear fit to the data gives the slope values as needed to evaluate $C_{\gamma}$ as $-8.414 \times 10^{-6} \mathrm{~N} / \mathrm{m}-\mathrm{K}$.

Using the information of slopes from figure 2 as well as using other input parameters from table 1 , the temperatureindependent intermediary terms in Eq. (14) are obtained. Using all the above values and $f_{\theta}\left(T_{\mathrm{s}}=298.15 \mathrm{~K}\right)=$ $\left(V_{\text {air }} /\left(\pi r^{3}\right)-H_{\text {air }} / r\right)=0.190021$ (from Eq. (8b)) as initial value in the RK4 method, the function $f_{\theta}(T)$ is calculated for different constant temperatures. Those values of $T$ and $f_{\theta}(T)$ along with the density values of water at those temperatures from Dean [52] are substituted in Eq. (16) to calculate the capillary pressure, $P_{\mathrm{c}}$ (figure 3 ). Even though the results are shown as a continuous line, the values of $P_{\mathrm{c}}$ at different temperatures are distinct. The subsurface temperature range fluctuates typically, as an example, around $5-10 \mathrm{~K}$ throughout the year as measured by Popiel et al [60] at Poznan city in Poland. Therefore we have assumed $\Delta T=10 \mathrm{~K}(298.15-308.15 \mathrm{~K})$ to test our theory and comparison purposes only. Temperatures can further be increased or decreased as your chosen preference with a known initial value. Here the assumption is that temperature range is always within certain $\Delta T$ to maintain CLP, as mentioned earlier during derivation. It has been checked for further values and it is found that it follows the same trend. For brevity, these results are not included in this paper.

\subsection{Example 2 (solid: polytetrafluoroethylene or PTFE and liquid: $n$-hexadecane)}

In the second example, a polytetrafluoroethylene-n-hexadecane-air $(\mathrm{P}-\mathrm{N}-\mathrm{A})$ combination is considered as the gas-liquid-solid system. The physical parameters as well as the ambient conditions and the size of the capillary are the
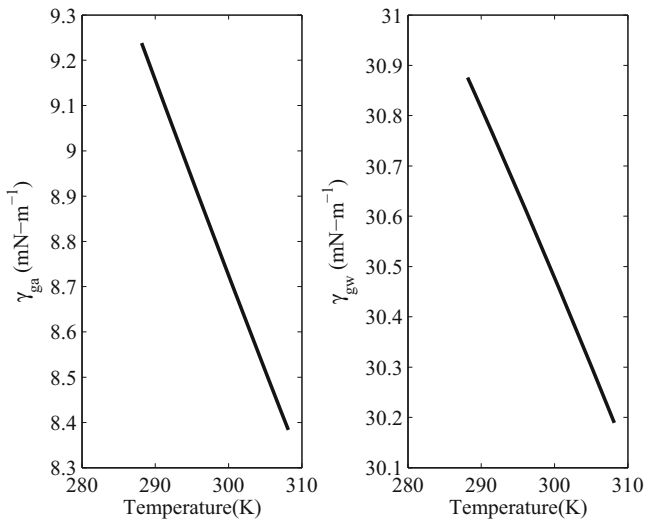

Figure 2. Interfacial tension of glass-air and of glass-water $v s$. temperature plots $\left(\gamma_{\mathrm{ga}}\right.$ vs. $T$ and $\gamma_{\mathrm{gw}}$ vs. T).

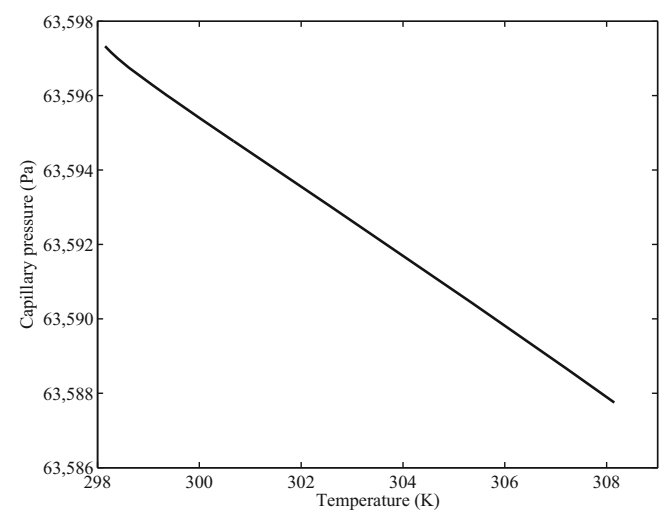

Figure 3. Capillary pressure vs. temperature plot for G-W-A system.

same as in Example 1 (figure 1). The relevant basic parameters for this study are given in table 2 .

Let the temperature of air throughout in the empty closed-end cylindrical PTFE tube be initially at $298.15 \mathrm{~K}$ (figure 1). Values of surface tension and equilibrium contact angle of n-hexadecane on PTFE at STP are taken from Neumann et al [64]. Density values of n-hexadecane are taken from the website of Dortmund Data Bank [65]. Values of $H_{\text {air }}$ and $n$ are obtained in the same way as suggested in Example 1 using the values of basic 
Table 2. Parameters used for calculation in PTFE-n-hexadecane-air system.

\begin{tabular}{cccc}
\hline Parameter & Description & Value & Reference \\
\hline$\sigma$ & Surface tension of n-hexadecane at $298.15 \mathrm{~K}$ & $27.09 \times 10^{-3} \mathrm{~N} / \mathrm{m}$ & Vargaftik et al $[63]$ \\
$\rho$ & Density of n-hexadecane at STP & $771.44 \mathrm{~kg} / \mathrm{m}^{3}$ & Dean [52] \\
$g$ & Acceleration due to gravitation & $9.81 \mathrm{~m} / \mathrm{s}^{2}$ & Mohr et al [58] \\
$\theta_{\mathrm{eq}}$ & Equilibrium contact angle of n-hexadecane on PTFE & $46^{\circ}$ & Neumann [62] \\
$r$ & Radius of the tube & $50 \times 10^{-6} \mathrm{~m}$ & Assumed \\
$R$ & Universal gas constant & $8.314 \mathrm{~N}-\mathrm{m} / \mathrm{K}$-mol & Mohr et al [58] \\
$H_{\mathrm{T}}$ & Total PTFE tube height & $0.20 \mathrm{~m}$ & Assumed \\
\hline
\end{tabular}

parameters from table 2. As far as calculation of interfacial tensions $\gamma_{\text {PTFE-air }}$ and $\gamma_{\text {PTFE-n-hexadecane }}$ are concerned, they are directly extracted from the experimental results of Neumann et al [64] (reproduced in figure 4). These values can also be obtained from Eqs. (17) and (18) as before. The $\gamma_{\text {PTFE-air }} v s$. $T$ and $\gamma_{\text {PTFE-n-hexadecane }} v s$. $T$ graphs are plotted (figure 4) and the difference in slopes $\left(C_{\gamma}=-5.643 \times 10^{-5} \mathrm{~N} / \mathrm{m}-\mathrm{K}\right)$ is obtained from linear fit to those data. Using all these values, the intermediary terms of Eq. (14) are calculated; putting the initial value of $f_{\theta}\left(T_{\mathrm{s}}=\right.$ $298.15 \mathrm{~K}$ ) as 0.213005 in the RK4 method, Eq. (14) is solved for different temperatures. As before, the capillary pressure is calculated and plotted against those temperatures (figure 5) using $f_{\theta}(T)$ values in Eq. (14) through $H_{\mathrm{m}}(T), V_{\text {air }}(T)$ and density $v s$. temperature data $(\rho(T))$ (Dortmund Data Bank [65]).

\section{Discussion}

Results show a linear decrease in capillary pressure as temperature rises. This is consistent with experimental results $[33,66]$, though here is the case for dead-end pores. Grant [34] suggested this phenomenon to be a universal one, i.e. capillary pressure follows a decreasing linear relationship with temperature for almost every system. In our case, two examples consist of two very different
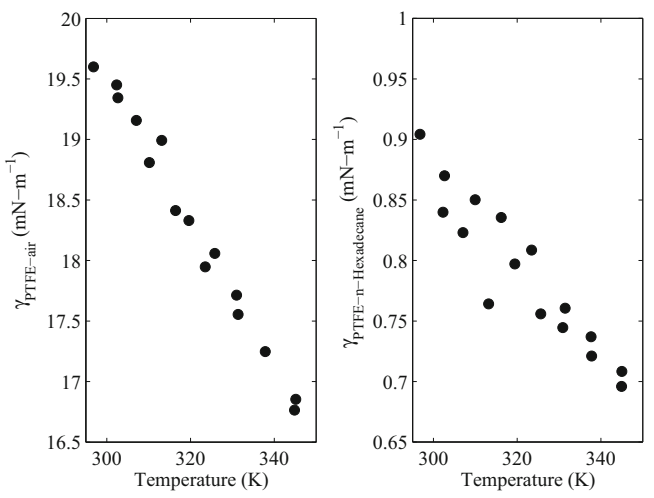

Figure 4. Interfacial tension of PTFE-air and of PTFE-n-hexadecane $v s$. temperature plots $\left(\gamma_{\mathrm{PTFE}-\text { air }} v s . T\right.$ and $\left.\gamma_{\mathrm{PTFE}-\mathrm{n} \text {-hexadecane }} v s . T\right)$ reproduced from figure 1 of Neumann et al [64]. systems and yet follow the same trend. However, the volume of gas in the tube decreases with the raising of the liquid. The gas law suggests that the pressure of the gas in the capillary should increase during the capillary rise of liquid while other state variables remain constant. Therefore, while temperature changes, the gas and liquid pressures both respond differently. Densities of liquid and gas, i.e. the packing of molecules and intermolecular forces between molecules, are different in liquid and in gas or ideal gas (where there are no intermolecular forces and interactions) and they behave differently as temperature changes. To understand these pressures and to get a better view of what is going on, air and liquid pressure for $\mathrm{G}-\mathrm{W}-$ $\mathrm{A}$ and $\mathrm{P}-\mathrm{N}-\mathrm{A}$ systems are shown disparately in figures 6 and 7. These pressures are just across the air-liquid interface (just below and above the interface).

Figures 6 and 7 show that pressure in liquid for both cases increases with temperature whereas air pressure reduces with temperature. However, air pressure in $\mathrm{P}-\mathrm{N}-\mathrm{A}$ system changes more with temperature than that of $\mathrm{G}-\mathrm{W}-\mathrm{A}$ system and hence it eventually affects the capillary pressure more. It is interesting to know whether there is an intrinsic reason for this or it is something extrinsic or a combination of these two.

For these examples, the radius $(r)$ and the total height $\left(H_{\mathrm{T}}\right)$ of the capillary tube are assumed. However, the importance of these parameters on capillary pressure is not ascertained and therefore the exercises are done to evaluate

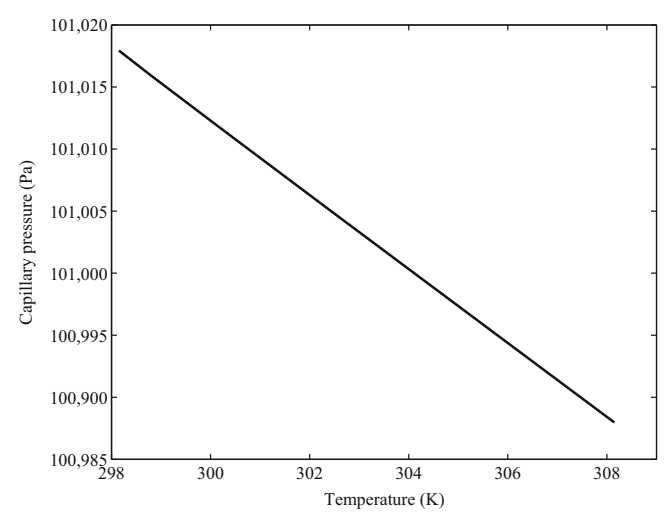

Figure 5. Capillary pressure $v$ s. temperature plot for $\mathrm{P}-\mathrm{N}-\mathrm{A}$ system. 


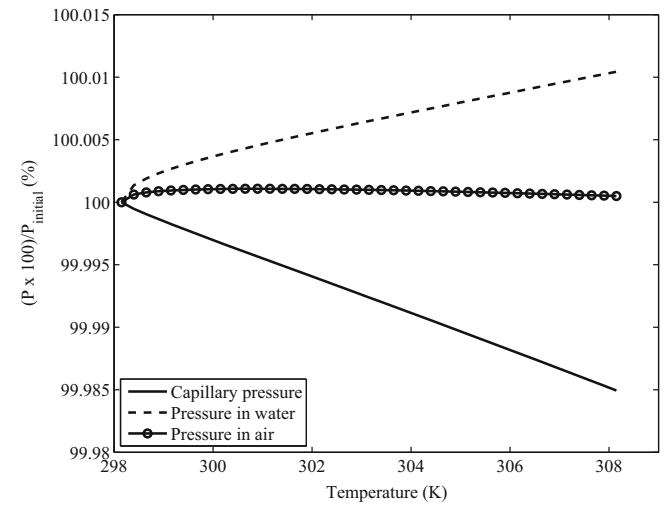

Figure 6. Variations (\%) of capillary pressure and pressures in air and water $v s$. temperatures are plotted for $\mathrm{G}-\mathrm{W}-\mathrm{A}$ system. $P$ stands for pressure. $P_{\text {initial }}$ means the pressure at reference temperature $298.15 \mathrm{~K}$.

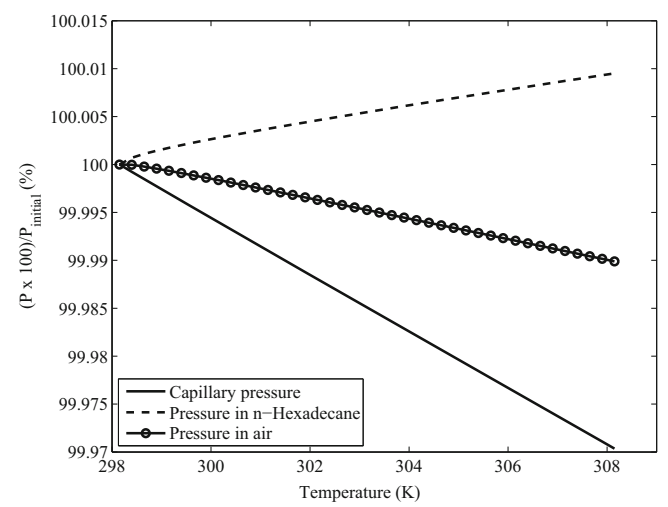

Figure 7. Variations (\%) of capillary pressure and pressures in air and n-hexadecane $v$ s. temperatures are plotted for $\mathrm{P}-\mathrm{N}-\mathrm{A}$ system. $P_{\text {initial }}$ is the pressure at reference temperature $298.15 \mathrm{~K}$.

capillary pressures for different values of $H_{\mathrm{T}}$ and $r$ (figures $8-11$ and $12-15$, respectively).

The analyses substantiate that both the physical dimensional factors are important while calculating the capillary pressure from the fact that the magnitudes of capillary pressure drastically change with the change in radius and total height of the tube. Since the top end of the capillary tube is closed, and as per the assumption that gas solubility in liquid is null, the numbers of gas molecules before the capillary rise and after attaining the Jurin height remain the same.

Figures 8-15 reveal one important thing about the entrapment of air and its effects of temperature variation on capillary pressure. As the height of the tube increases, for cases involving the same Jurin height and the same parameters, the volume for the entrapped air is more. Therefore, the magnitude of air pressure is less for higher tubes as compared with the shorter tubes. Similarly, the capillary pressure is high for shorter tubes as the entrapped space for air is low. For very long vertical tubes, the
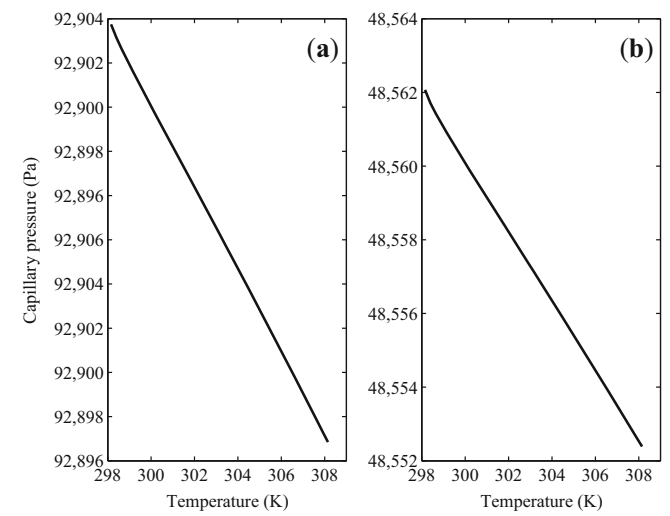

Figure 8. Capillary pressure $v s$. temperature plots. Plots for GW-A system with (a) $H_{\mathrm{T}}=0.40 \mathrm{~m}$ and (b) $0.60 \mathrm{~m}$.
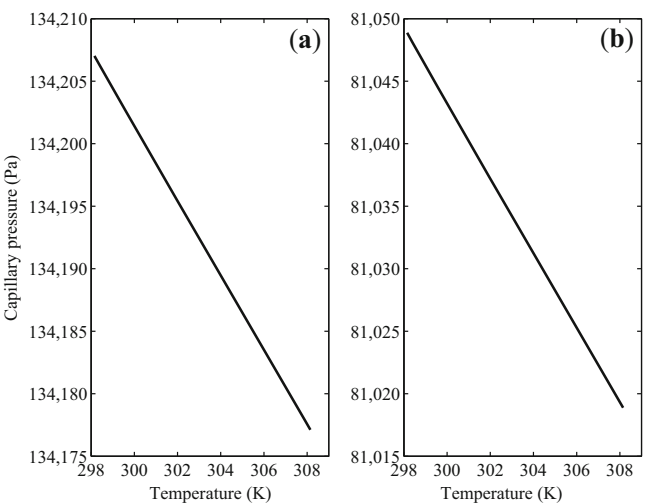

Figure 9. Capillary pressure vs. temperature plots. Plots for $\mathrm{P}-$ $\mathrm{N}-\mathrm{A}$ system with (a) $H_{\mathrm{T}}=0.175 \mathrm{~m}$ and (b) $0.225 \mathrm{~m}$.

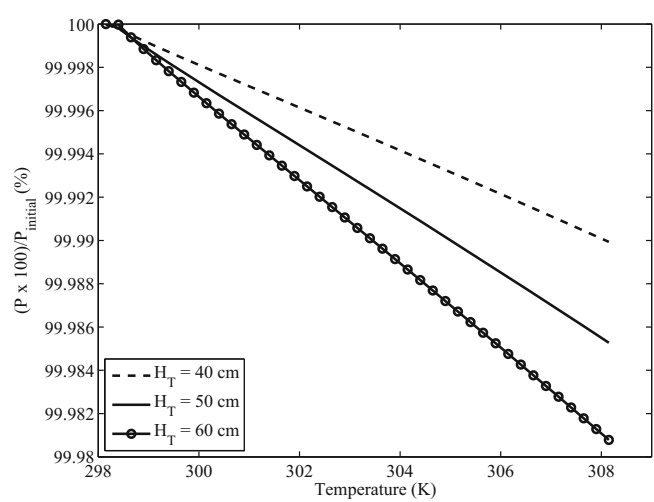

Figure 10. Variation (\%) of capillary pressure vs. temperature for G-W-A system with $H_{\mathrm{T}}=0.40,0.50$ and $0.60 \mathrm{~m}$. $P_{\text {initial }}$ means the pressure at reference temperature $298.15 \mathrm{~K}$.

entrapped air gets more space, which decreases the gaseous pressure, and they behave more like open-end tubes. Figures 10-15 show that with increasing $r$ and $H_{\mathrm{T}}$, capillary pressure becomes sensitive to temperature more and more for both example cases. 


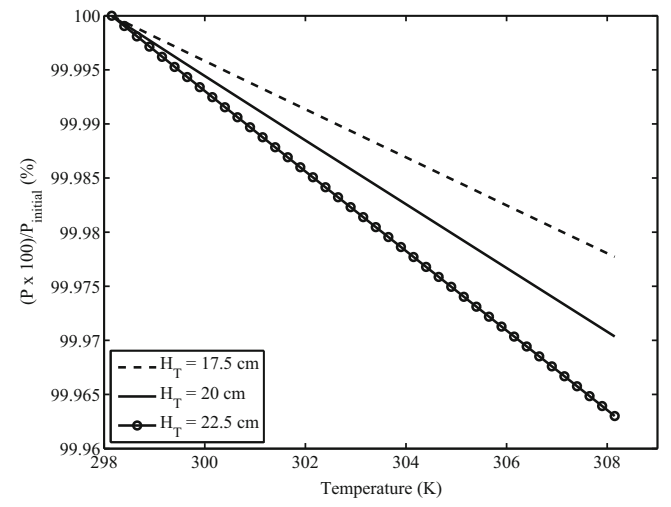

Figure 11. Variation (\%) of capillary pressure vs. temperature for P-N-A system with $H_{\mathrm{T}}=0.175,0.20$ and $0.225 \mathrm{~m}$. $P_{\text {initial }}$ means the pressure at reference temperature $298.15 \mathrm{~K}$.
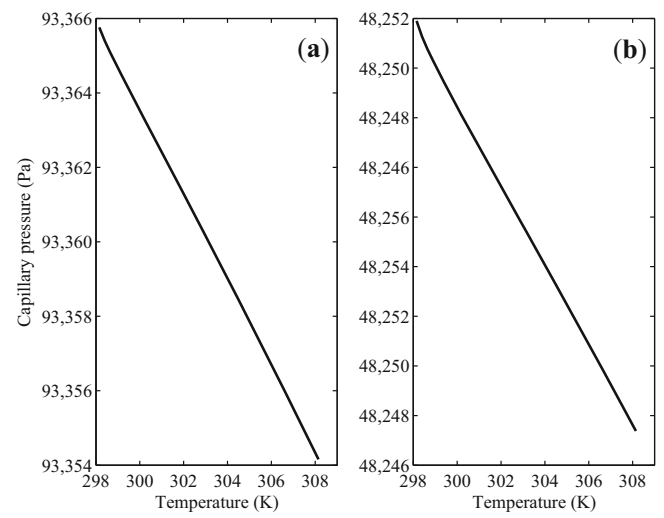

Figure 12. Capillary pressure $v s$. temperature plots. Plots for GW-A system with (a) $r=40 \mu \mathrm{m}$ and (b) $60 \mu \mathrm{m}$.
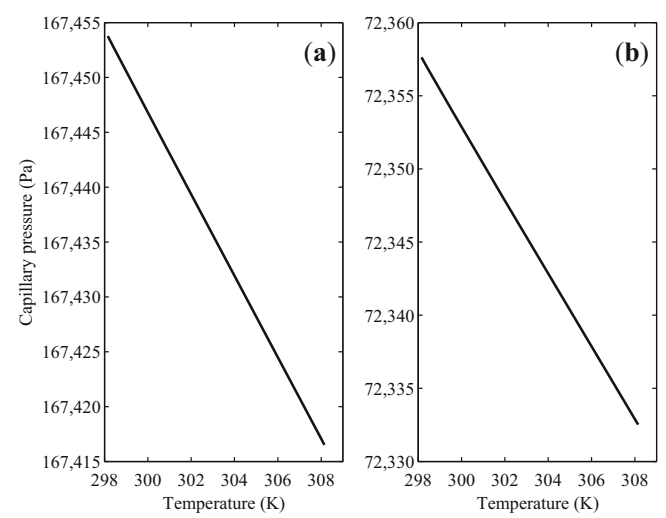

Figure 13. Capillary pressure vs. temperature plots. Plots for P$\mathrm{N}-\mathrm{A}$ system with (a) $r=40 \mu \mathrm{m}$ and (b) $60 \mu \mathrm{m}$.

\subsection{Open-end capillary tube}

The thermal effects of capillary pressures in open-end tubes are briefly investigated after seeing the effects of vertical length on capillary pressure in closed-end tubes. With the same explanation provided for the temperature effects on

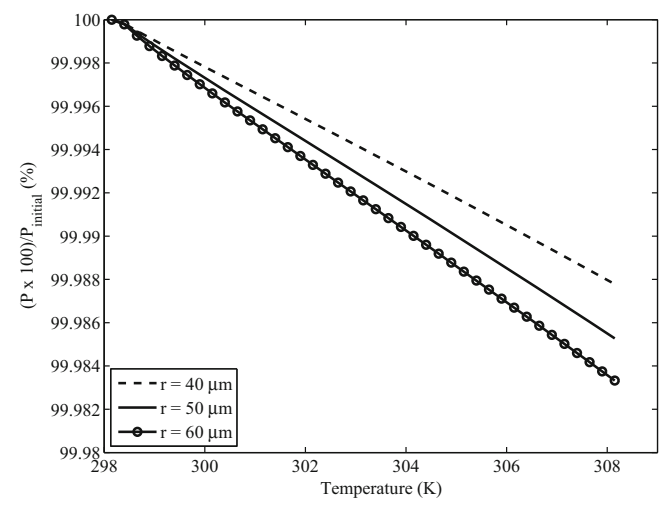

Figure 14. Variation (\%) of capillary pressure vs. temperature for G-W-A system with $r=40,50$ and $60 \mu \mathrm{m}$. $P_{\text {initial }}$ is the pressure at reference temperature $298.15 \mathrm{~K}$.

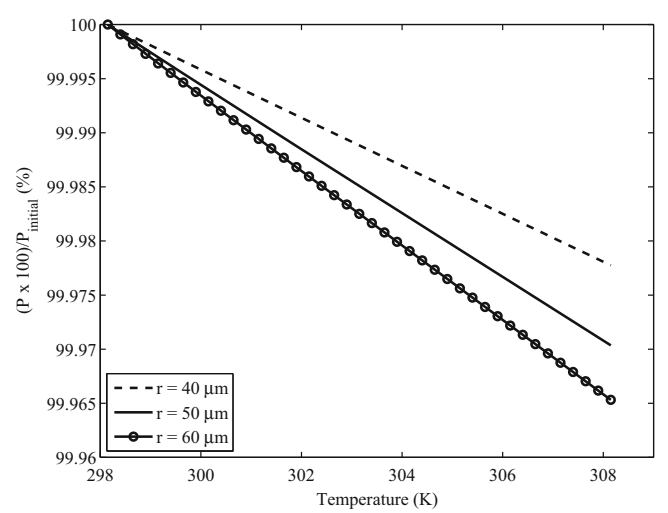

Figure 15. Variation $(\%)$ of capillary pressure $v s$. temperature for $\mathrm{P}-\mathrm{N}-\mathrm{A}$ system with $r=40,50$ and $60 \mu \mathrm{m}$. $P_{\text {initial }}$ is the pressure at reference temperature $298.15 \mathrm{~K}$.

capillary pressure for closed-end tubes, the concept is extended to describe the effects of temperature on capillary pressure in open-end capillary tubes. However, the mathematical expressions (or equations) are modified to take into account the difference in gas pressure at the open end of the capillary. The gas or air pressure can be evaluated as in Maggi and Alonso-Marroquin [67] from the following expression:

$$
P_{\text {air }}(T)=P_{\text {atm }}-\rho_{\text {air }}(T) g H_{\mathrm{T}},
$$

where $P_{\text {atm }}$ is the pressure at the phreatic surface of the water table outside the tube (which is atmospheric pressure) and $P_{\text {air }}$ is the pressure in air just at the top of the tube (assumed to be the same as that inside in the tube). Since the open end provides room for escape of gas molecules, the density of air, as well as the volume of air, differs significantly from that of closed-end tubes. Substituting $P_{\text {air }}(T)$ in lieu of $(n R T) /\left(V_{\text {air }}\left(f_{\theta}(T)\right)\right)$ in Eq. (16) and using Eq. (19), one gets 


$$
P_{\mathrm{c}}(T)=-g \rho_{\text {air }}(T) H_{\mathrm{T}}+g \rho(T)\left(H_{\text {liquid }}-H_{\mathrm{m}}\left(f_{\theta}(T)\right)\right) .
$$

The same calculations and solution procedures as performed for the closed-end tube are repeated to find $f_{\theta}(T)$ from Eq. (14). We used the same data sets of Examples 1 and 2 that were used for closed-end capillary tubes, here, for open-end pore problems. After solving for $f_{\theta}(T)$ in Eq. (14), it is substituted in Eq. (12) to consequently evaluate $H_{\mathrm{m}}\left(f_{\theta}(T)\right)$. Using a fitting relationship of temperature and density of the liquid (as used before) and of air $\left(\rho_{\text {air }}(T)\right)$ [68], the capillary pressures are computed for different temperatures (figure 16).

In the case of open-end pores, the magnitude of capillary pressure is lower than that of closed-end pores. This is due to the escape of gas molecules through the open end during the capillary rising of liquid. For both the closed-end as well as the open-end capillary pores, the capillary pressure reduces linearly due to increasing temperature and thus proves the claim of Grant [34] as mentioned before about the universality of the trend of linear drop of temperature $v s$. capillary pressure relationship. However, one of the reasons may be that the increase in temperature excites the gas particles and this excitation raises the velocity of air molecules and thus the momentum of gas particles. Consequently, it forces the solids and liquids and expands the gas volume more compared with the liquid volume. Therefore, the difference between gas pressure and liquid pressure gets reduced as temperature rises and thereby causes a reduction in capillary pressure. Another observation is that capillary pressure is more sensitive to temperature in open-end than that of dead-end pore system, and figure 17 reveals this fact as the percentage drop of $P_{\mathrm{c}}$ at $298.15 \mathrm{~K}$ from $-0.015 \% / \mathrm{K}$ (dead-end) to $-0.551 \% / \mathrm{K}$ (openend) for $\mathrm{G}-\mathrm{W}-\mathrm{A}$ whereas it is $-0.030 \% / \mathrm{K}$ (dead-end) to $-1.263 \% / \mathrm{K}$ (open-end) for $\mathrm{P}-\mathrm{N}-\mathrm{A}$. It can be hypothesized following figures $8-15$ that the capillary pressures in very long closed-end capillary tubes may behave almost the same way as in open-end tubes. Entrapment length of air or $H_{\text {air }}$ (see figure 1) has an important role in capillary pressure
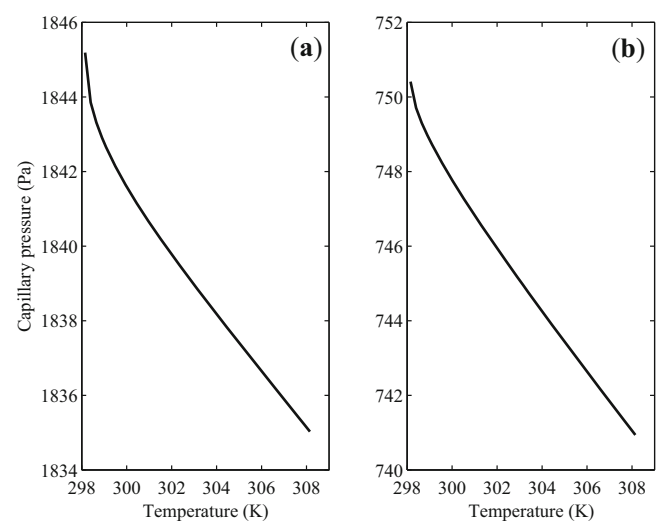

Figure 16. Capillary pressure $v s$. temperature plot for (a) G-WA system (open-end) and (b) P-N-A system (open-end). magnitude. Equilibrium contact angle also has an effect on $P_{\mathrm{c}}(T)$. Slope values of $P_{\mathrm{c}} v s . T$, while changing $\theta_{\mathrm{eq}}$ in deadend cases, can vary from $-1.04 \mathrm{~Pa} / \mathrm{K}$ (with $\theta_{\mathrm{eq}}=40^{\circ}$ ) to $-0.824 \mathrm{~Pa} / \mathrm{K}$ (with $\theta_{\mathrm{eq}}=60^{\circ}$ ) for $\mathrm{G}-\mathrm{W}-\mathrm{A}$, and from -3.102 $\mathrm{Pa} / \mathrm{K}$ (with $\theta_{\mathrm{eq}}=36^{\circ}$ ) to $-2.855 \mathrm{~Pa} / \mathrm{K}$ (with $\theta_{\mathrm{eq}}=56^{\circ}$ ) for $\mathrm{P}-\mathrm{N}-\mathrm{A}$. Soil pore size (radius) can range from $\sim 0.05 \mu \mathrm{m}$ ('cryptopore') to $2500 \mu \mathrm{m}$ ('macropore') [56]. The dimension of the capillary tube along with $\theta_{\text {eq }}$ can give an idea of an approximate range of slope values for the dead-end case. With pore radius changing from 1 (with $\theta_{\mathrm{eq}}=10^{\circ}$ ) to 1000 $\mu \mathrm{m}$ (with $\theta_{\mathrm{eq}}=80^{\circ}$ ) with $H_{\mathrm{T}}=150 \mathrm{~m}$ while keeping other terms constant in the case of $\mathrm{G}-\mathrm{W}-\mathrm{A}$, slope changes from $\sim-57.9$ to $-4 \mathrm{~Pa} / \mathrm{K}$ and similarly in the case of $\mathrm{P}-\mathrm{N}-\mathrm{A}$ but only with $H_{\mathrm{T}}=7.5 \mathrm{~m}$, slope changes from $\sim-162.4$ to -1.2 $\mathrm{Pa} / \mathrm{K}$. Therefore $10 \mathrm{~K}$ change in temperature can drop the capillary pressure from 12-40 to 579-1624 Pa. Nevertheless, for both cases, the linear drop of capillary pressure with temperature is observed, even though the two are very different systems. This validates the equation derived in this paper qualitatively if not quantitatively [33] as only a single capillary tube is considered and dealt with. Grant [34] mentioned that relative drop in capillary pressure at $298 \mathrm{~K}$ is typically around $-1 \% / \mathrm{K}$, and the early results show the relative drop at $298.15 \mathrm{~K}$ to be around $-0.551 \% / \mathrm{K}$ and $-1.263 \% / \mathrm{K}$ for $\mathrm{G}-\mathrm{W}-\mathrm{A}$ and $\mathrm{P}-\mathrm{N}-\mathrm{A}$, respectively.

As $P_{\mathrm{c}}$ is found to vary linearly with $T$, Eq. (16) can be replaced with a simple linear relation: $P_{c}=a_{0}+a_{1} T$, where $a_{0}(\mathrm{~Pa})$ and $a_{1}(\mathrm{~Pa} / \mathrm{K})$ are fitting parameters. Following figures 3 and 5, $a_{0}$ and $a_{1}$ can be obtained: (1) for G-W-A system, $a_{0}=63877.437 \mathrm{~Pa}$ (standard error or SE: 0.515), $a_{1}=-0.939 \mathrm{~Pa} / \mathrm{K}$ (SE: 0.002); (2) for $\mathrm{P}-\mathrm{N}-\mathrm{A}$ system, $a_{0}=101909.086 \mathrm{~Pa}(\mathrm{SE}: 0.466), a_{1}=-2.989 \mathrm{~Pa} / \mathrm{K}$ (SE: 0.002). This simple relation may hold for most systems but does miss out some intricate physics underneath. Empirical relationships of physical parameters and temperature are nowadays easily available or can be obtained through standard experiments. Equation (16) gives much
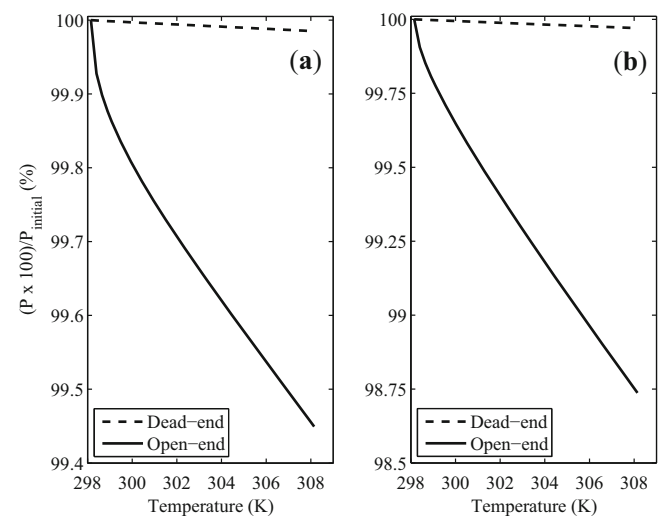

Figure 17. Comparison plots of capillary pressures in dead-end and open-end capillary systems. Variation (\%) of capillary pressure vs. temperature plots for both (a) G-W-A and (b) $\mathrm{P}-$ N-A systems. $P_{\text {initial }}$ means pressure at reference temperature $298.15 \mathrm{~K}$. 
broader picture than that of a one-parameter or two-parameter model. Here, two generic cases are solved as the data of these materials are available. With regard to heterogeneous soils, depending upon soil chemistry and thermal experiments upon soil, the temperature dependence of physical properties like $\rho_{\text {liquid }} v s$. $T, \sigma_{\text {liquid }} v s$. $T$ (as in [52]), $\theta_{\text {liquid-on-soil }} v s . T$ (as in [69]), etc. can be obtained and then utilized as input parameters in similar example problems described earlier. Dead-end pores can be identified by some conventional methods (electric logging formation factor, mercury injection capillary pressure and miscible displacement, etc.) as mentioned by Jackson and Klute [21] or as mentioned by Fatt et al [70] and most recently by Phirani et al [71] and these methods can provide an effective size as well as the volumetric fraction of dead-end pores. The method proposed here can be modified or extended to deal with the more generic cases like the liquid flux. Thermal gradient of capillary pressure contributes to the liquid flux in unsaturated soil as $-K \frac{\partial \psi}{\partial T} \nabla T$ [72], where $K$ is the unsaturated hydraulic conductivity (m/ s) and $\psi=P_{\mathrm{c}} /(\rho g)(\mathrm{m})$. The term $\frac{\partial \psi}{\partial T}$ can be decomposed into three parts as

$$
\begin{gathered}
\frac{\partial \psi}{\partial T}=\underbrace{\left.\omega_{\mathrm{D}} \frac{\partial \psi}{\partial T}\right|_{\text {dead-end }}+\left.\omega_{\mathrm{O}} \frac{\partial \psi}{\partial T}\right|_{\text {open-end }}}_{\text {unsaturated }}+\underbrace{\omega_{\mathrm{S}} \times 0}_{\text {saturated }} \\
\text { with } \omega_{\mathrm{D}}+\omega_{\mathrm{O}}+\omega_{\mathrm{S}}=1 \text { and } \omega \in[0,1] .
\end{gathered}
$$

Here three weighting factors $(\omega)$ indicate volumetric fraction of dead-end pore $\left(\omega_{\mathrm{D}}\right)$ (saturated or unsaturated), of open-end unsaturated pores $\left(\omega_{\mathrm{O}}\right)$ and of open-end saturated pore $\left(\omega_{\mathrm{S}}\right)$ relative to total void in an averaging volume of soil. When the entire soil is saturated, the temperature derivative term becomes zero and does not contribute to actual liquid flux. However, we limit the present study as described here and suggest the generic cases as future scope along with sophisticated experimentations.

\section{Conclusions}

The dead-end pores are assumed to be capillary tubes with one end closed and the effect of temperature on liquid-gas meniscus is analysed. The shape of the meniscus in the capillary tube is considered to be spherical. As the translation displacement of the meniscus is neglected, the effect of temperature on capillary pressure is worked out by first identifying the change in meniscus curvatures due to incremental variation in temperature and thereby the changes in the interfacial tensions that consequently cause the change in capillary pressures. This whole concept is represented using a differential equation in this paper, in which the dependent variable is a new term called temperature function. The differential changes in meniscus height $\left(H_{\mathrm{m}}\right)$ were evaluated. Thus the capillary pressure is calculated from meniscus height values and density values at different temperatures relative to a chosen reference temperature. For both the $\mathrm{G}-\mathrm{W}-\mathrm{A}$ and $\mathrm{P}-\mathrm{N}-\mathrm{A}$ systems, the results show a linear drop of capillary pressure with temperature. An important observation in dead-end pores or closed-end tubes is that of the significance of entrapped air in terms of $r$ and $H_{\text {air }}$ as well as the value of $\theta_{\text {eq }}$ in computations of capillary pressure at different constant temperatures. The effect of temperature on liquid-gas meniscus in the open-end capillary tube also showed a linear drop of capillary pressure with temperature. However, the magnitudes of capillary pressures are much lower compared with the dead-end pore cases. Closed-end capillary tube with very large air column at the top behaves approximately like the open-end tube with respect to capillary pressure vs. temperature relationship. The results presented here are consistent with the experimental data qualitatively. In addition, the paper, for the first time, provides a conceptual insight into the significance of dead-end pores on the capillary pressure $v s$. temperature relationship or on CPSR at a particular liquid saturation or on the thermal component of liquid flux. Further research could focus on robust porescale modeling through novel experiments and instrumentation on dead-end pores as well as on soil as a whole.

\section{Acknowledgements}

The authors are thankful to the corresponding editor, Prof. S. Murty Bhallamudi and the anonymous reviewer(s), for their valuable comments and suggestions to improve the manuscript. The first author gratefully acknowledges the Ministry of Human Resource Development (MHRD), Government of India, for providing Ph.D. scholarship during this work.

\section{List of symbols}

$a \quad$ fitting parameter

Bo $\quad$ Bond number $\left(=\rho g r^{2} / \sigma\right)$

$C_{\gamma} \quad\left(d \gamma_{\mathrm{sa}} / d T-d \gamma_{\mathrm{sl}} / d T\right)(\mathrm{N} / \mathrm{m}-\mathrm{K})$

$\Delta T$ range of temperatures $(\mathrm{K})$

$f_{\theta} \quad$ contact-angle-sensitive temperature function

$G \quad$ temperature-dependent variables

$\gamma \quad$ interfacial tension $(\mathrm{N} / \mathrm{m})$

$g$ acceleration due to gravitation $\left(\mathrm{m} / \mathrm{s}^{2}\right)$

$h$ Jurin height (m)

$H$ height (m)

$K$ unsaturated hydraulic conductivity $(\mathrm{m} / \mathrm{s})$

$M$ temperature-independent variables

$\mathcal{M}$ molar mass $(\mathrm{kg} / \mathrm{mol})$

$n$ number of moles of gas (mol)

$\omega$ weighting factor $\left(\mathrm{m}^{3} / \mathrm{m}^{3}\right)$

$P$ pressure $(\mathrm{Pa})$

$P^{\prime} \quad$ hydrostatic pressure $(=-\rho g h)(\mathrm{Pa})$ 
$r \quad$ radius of the capillary tube (m)

$\rho \quad$ liquid density $\left(\mathrm{kg} / \mathrm{m}^{3}\right)$

$R \quad$ universal gas constant $(\mathrm{N}-\mathrm{m} / \mathrm{K}-\mathrm{mol})$

$\sigma \quad$ surface tension of liquid $(\mathrm{N} / \mathrm{m})$

$\psi \quad$ capillary potential or head $(\mathrm{m})$

$T$ temperature (K)

$\theta \quad$ contact angle (deg)

$V \quad$ volume $\left(\mathrm{m}^{3}\right)$

$\mathcal{V}$ molar volume $\left(\mathrm{m}^{3} / \mathrm{mol}\right)$

\section{Subscripts}

atm atmospheric

c capillary

D dead-end

eq equilibrium

f final

g glass

i initial

m meniscus

O open-end

p particular

ref reference

s standard

$\mathrm{S} \quad$ saturated

sa solid-air

sl solid-liquid

$\mathrm{T}$ total

w water

\section{References}

[1] Bear J and Cheng A H D 2010 Modeling groundwater flow and contaminant transport. Berlin: Springer Science and Business Media, pp. 261-266

[2] Brooks R H and Corey A T 1964 Hydraulic properties of porous media and their relation to drainage design. Trans. ASAE 7: 0026-0028

[3] van Genuchten M T 1980 A closed-form equation for predicting the hydraulic conductivity of unsaturated soils. Soil Sci. Soc. Am. J. 44: 892-898

[4] Richards L A 1931 Capillary conduction of liquids through porous mediums. J. Appl. Phys. 1: 318-333

[5] Clayton W S 1999 Effects of pore scale dead-end air fingers on relative permeabilities for air sparging in soils. Water Resour. Res. 35: 2909-2919

[6] Bear J 1972 Dynamics of fluids in porous media. New York: Dover Publications, Inc., p. 44

[7] Lenhard R J and Parker J C 1987 A model for hysteretic constitutive relations governing multiphase flow: 2. Permeability-saturation relations. Water Resour. Res. 23: 2197-2206

[8] Barua G and Sarmah R 2016 An analytical solution for predicting transient seepage into partially penetrating ditch drains receiving water from a ponded field. Acta Geophys. 64: 149-205

[9] Ritzema H P 2006 Drainage principles and applications. No. 16, International Institute for Land Reclamation and Improvement, Wageningen, Netherlands, p. 533
[10] Huang S, Pollack H N and Shen P Y 2000 Temperature trends over the past five centuries reconstructed from borehole temperatures. Nature 403: 756

[11] Benz S A, Bayer P, Winkler G and Blum P 2018 Recent trends of groundwater temperatures in Austria. Hydrol. Earth Syst. Sci. 22: 3143-3154

[12] Howard L 1833 Climate of London deduced from meteorological observation, vol. 3. London: Harvey and Dorton

[13] Zheng D, Hunt Jr E R and Running S W 1993 A daily soil temperature model based on air temperature and precipitation for continental applications. Climate Res. 2: 183-191

[14] Xie Z and Cao H X 1996 Asymmetric changes in maximum and minimum temperature in Beijing. Theor. Appl. Climatol. 55: $151-156$

[15] Yalcin T and Yetemen O 2009 Local warming of groundwaters caused by the urban heat island effect in Istanbul, Turkey. Hydrogeol. J. 17: 1247-1255

[16] Barman D, Kundu D K, Pal S, Pal S, Chakraborty A K, Jha A K, Mazumdar S P, Saha R and Bhattacharyya P 2017 Soil temperature prediction from air temperature for alluvial soils in lower Indo-Gangetic plain. Int. Agrophys. 31: 9-22

[17] Anderson M P 2005 Heat as a ground water tracer. Ground Water 43: 951-968

[18] Rodell M, Famiglietti J S, Wiese D N, Reager J T, Beaudoing H K, Landerer F W and Lo M H 2018 Emerging trends in global freshwater availability. Nature 557: 651-659

[19] Coats K H and Smith B D 1964 Dead-end pore volume and dispersion in porous media. Soc. Petrol. Eng. J. 4: 73-84

[20] Goodknight R C, Klikoff Jr W A and Fatt I 1960 Non-steadystate fluid flow and diffusion in porous media containing dead-end pore volume. J. Phys. Chem. 64: 1162-1168

[21] Jackson R D and Klute A 1967 Estimation of dead-end pore volume in soils from transient- and steady-state diffusion coefficients. Soil Sci. Soc. Am. J. 31: 122-123

[22] Philip J R 1968 Diffusion, dead-end pores, and linearized absorption in aggregated media. Aust. J. Soil Res. 6: 21-30

[23] De Smedt F and Wierenga P J 1979 A generalized solution for solute flow in soils with mobile and immobile water. Water Resour. Res. 15: 1137-1141

[24] Jamaloei B Y and Kharrat R 2009 Fundamental study of pore morphology effect in low tension polymer flooding or polymer-assisted dilute surfactant flooding. Transport Porous Med. 76: 199-218

[25] Kar A, Chiang T Y, Rivera I O, Sen A and Velegol D 2015 Enhanced transport into and out of dead-end pores. ACS Nano 9: 746-753

[26] Zhang L J and Yue X A 2008 Displacement of polymer solution on residual oil trapped in dead ends. J. Cent. South Univ. Technol. 15: 84-87

[27] Mosavat N and Torabi F 2016 Micro-optical analysis of carbonated water injection in irregular and heterogeneous pore geometry. Fuel 175: 191-201

[28] Santiago C, Ghomeshi S, Kryuchkov S and Kantzas A 2016 Pore level modeling of imbibition in heavy oil saturated media. J. Petrol. Sci. Eng. 140: 108-118

[29] Sedaghat M H, Hatampour A and Razmi R 2013 Investigating the role of polymer type and dead end pores' distribution on oil recovery efficiency during ASP flooding. Egypt. J. Petrol. 22: 241-247

[30] Fatt I 1961 Influence of dead-end pores on relative permeability of porous media. Science 134: 1750-1751 
[31] Grant S A and Salehzadeh A 1996 Calculation of temperature effects on wetting coefficients of porous solids and their capillary pressure functions. Water Resour. Res. 32: 261-270

[32] Bachmann J and van der Ploeg R R 2002 A review on recent developments in soil water retention theory: interfacial tension and temperature effects. J. Plant Nutr. Soil Sci. 165: 468-478

[33] Grant S A and Bachmann J 2002 Effect of temperature on capillary pressure. In: Raats P A C, Smiles D and Warrick A W (Eds.) Environmental mechanics: water, mass and energy transfer in the biosphere: the Philip volume. Washington, DC: American Geophysical Union, pp. 199-212

[34] Grant S A 2003 Extension of a temperature effects model for capillary pressure saturation relations. Water Resour. Res. 39: SBH 1-10

[35] Gao H and Shao M 2015 Effects of temperature changes on soil hydraulic properties. Soil Till. Res. 153: 145-154

[36] Faybishenko B 1983 Effect of temperature on moisture content, entropy, and water pressure in loam soils (In Russian). Pochvevedenie 12: 43-48

[37] Lu N and Likos W J 2004 Unsaturated soil mechanics. New Jersey: John Wiley and Sons Inc., pp. 128-133

[38] Hassanizadeh S M and Gray W G 1993 Thermodynamic basis of capillary pressure in porous media. Water Resour. Res. 29: 3389-3405

[39] De Gennes P G, Brochard-Wyart F and Quéré D 2004 Capillarity and wetting phenomena: drops, bubbles, pearls, waves. New York: Springer, pp. 6-9, 52-53

[40] Çengel Y A and Boles M A 2015 Thermodynamics: An engineering approach, 8th edition. New York: McGraw-Hill, pp. 134-136

[41] Elliott G E P and Riddiford A C 1967 Dynamic contact angles: I. The effect of impressed motion. J. Colloid Interf. Sci. 23: 389-398

[42] Poynting J H and Thomson J J 1902 A textbook of physics properties of matter. London: Griffin

[43] Slattery J C and Flumerfelt F W 1982 Interfacial phenomena. In: Hetsron G (Ed.) Handbook of multiphase systems. New York: Hemisphere Publishing Corporation, Chapter 1, pp. 224-254

[44] Kuchin I V and Starov V M 2016 Hysteresis of the contact angle of a meniscus inside a capillary with smooth, homogeneous solid walls. Langmuir 32: 5333-5340

[45] Makkonen L 2017 A thermodynamic model of contact angle hysteresis. J. Chem. Phys. 147: 064703

[46] Johnson Jr R E and Dettre R H 1964 Contact angle hysteresis. III. Study of an idealized heterogeneous surface. $J$. Phys. Chem. 68: 1744-1750

[47] Marmur A 1994 Thermodynamic aspects of contact angle hysteresis. Adv. Colloid Interf. Sci. 50: 121-141

[48] Pompe T and Herminghaus S 2000 Three-phase contact line energetics from nanoscale liquid surface topographies. Phys. Rev. Lett. 85: 1930

[49] Quéré D 2008 Wetting and roughness. Annu. Rev. Mater. Res. 38: 71-99

[50] Whyman G, Bormashenko E and Stein T 2008 The rigorous derivation of Young, Cassie-Baxter and Wenzel equations and the analysis of the contact angle hysteresis phenomenon. Chem. Phys. Lett. 450: 355-359

[51] Hoffman J D 2001 Numerical methods for engineers and scientists, 2nd edition. New York: Marcel Dekker, Inc., pp. 372-376

[52] Dean J A 1999 Lange's handbook of chemistry. New York: McGraw-Hill, p. 5.87, 5.97, 5.134
[53] Çengel Y A and Boles M A 2006 Property tables booklet/ thermodynamics. New York: McGraw-Hill

[54] Biswas D and Kartha S A 2017 Temperature dependence of contact angle hysteresis. In: Barbosa Jr J R and Ribatski G (Eds.) Proceedings of the 9th World Conference on Experimental Heat Transfer, Fluid Mechanics, and Thermodynamics (ExHFT-9), Foz do Iguacu, Brazil, June 11-15, 2017, PT28

[55] Hager W H 2012 Wilfrid Noel Bond and the bond number. $J$. Hydraul. Res. 50: 3-9

[56] Soil Science Society of America 2008 Glossary of soil science terms 2008. ASA-CSSA-SSSA

[57] Liechti K M, Schnapp S T and Swadener J G 1997 Contact angle and contact mechanics of a glass/epoxy interface. Int. J. Fracture 86: 361-374

[58] Mohr P J, Taylor B N and Newell D B 2016 CODATA recommended values of the fundamental physical constants: 2014. Rev. Mod. Phys. 88: 035009

[59] Girifalco L A and Good R J 1957 A theory for the estimation of surface and interfacial energies. I. Derivation and application to interfacial tension. J. Phys. Chem. 61: 904-909

[60] Popiel C O, Wojtkowiak J and Biernacka B 2001 Measurements of temperature distribution in ground. Exp. Therm. Fluid Sci. 25: 301-309

[61] Seward III T P and Vascott T E 2005 High temperature glass melt property database for process modeling. Ohio: The American Ceramic Society

[62] Neumann A W 1974 Contact angles and their temperature dependence: thermodynamic status, measurement, interpretation and application. Adv. Colloid Interf. Sci. 4: 105-191

[63] Vargaftik N B, Volkov B N and Voljak L D 1983 International tables of the surface tension of water. J. Phys. Chem. Ref. Data 12: 817-820

[64] Neumann A W, Haage G and Renzow D 1971 The temperature dependence of contact angles polytetrafluoroethylene/ N-alkanes. J. Colloid Interf. Sci. 35: 379-385

[65] Onken U, Rarey-Nies J and Gmehlin J 1989 The Dortmund Data Bank: a computerized system for retrieval, correlation, and prediction of thermodynamic properties of mixtures. Int. J. Thermophys. 10: 739-747 (Website: http://www.ddbst. com, accessed 20 August 2015)

[66] She H Y and Sleep B E 1998 The effect of temperature on capillary pressure-saturation relationships for air-water and perchloroethylene-water systems. Water Resour. Res. 34: 2587-2597

[67] Maggi F and Alonso-Marroquin F 2012 Multiphase capillary flows. Int. J. Multiphase Flow 42: 62-73

[68] Golfman Y 2012 Hybrid anisotropic materials for wind power turbine blades. Florida: CRC Press, pp. 208-209

[69] Bachmann J, Horton R, Grant S A and van der Ploeg R R 2002 Temperature dependence of water retention curves for wettable and water-repellent soils. Soil Sci. Soc. Am. J. 66: 44-52

[70] Fatt I, Maleki M and Upadhyay R N 1966 Detection and estimation of dead-end pore volume in reservoir rock by conventional laboratory tests. Soc. Petrol. Eng. J. 6: 206-212

[71] Phirani J, Roy S and Pant H J 2018 Predicting stagnant pore volume in porous media using temporal moments of tracer breakthrough curves. J. Petrol. Sci. Eng. 165: 640-646

[72] Philip J R and de Vries D A 1957 Moisture movement in porous materials under temperature gradients. EOS Trans. Am. Geophys. Union 38: 222-232 